\title{
OBITUARY
}

\section{A tribute to Grant Gall}

Robert J Bailey

$\mathrm{I}_{\mathrm{a}}^{\mathrm{s}}$ is with much sadness that I write that Grant Gall died suddenly while on holiday with his wife Laurie. He might want it noted that it was with his 'older' wife Laurie because he loved to tease her over the two or three days difference in their birthdays. The two were inseparable over their 49 years of married life, and it is difficult to think of Grant without thinking of Laurie. He loved her tremendously as he did his children and grandchildren.

Grant had a great sense of humour and loved to laugh. Once in a while, he would gasp for a halt in the storytelling because he was laughing so hard that his not insubstantial girth was in pain. That is how I will remember him. He was a man with a passion for life. If you have only seen him in a shirt and tie at meetings, stop and imagine Grant in short pants, a T-shirt, walking shoes and a Tilly sun hat, bristling for the adventure at hand.

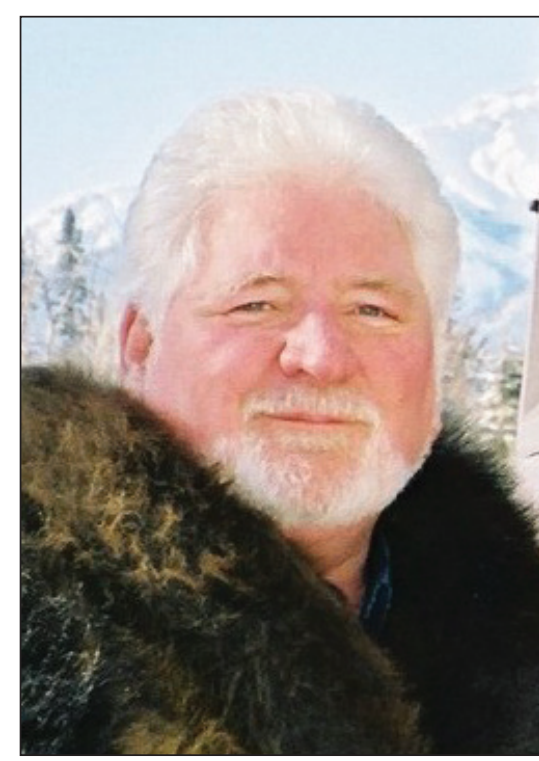

Grant Gall including chairing the Experimental Medicine Grant Review Committee. He supervised a successfully funded laboratory for more than 20 years and was recognized as a leader in intestinal adaptation and diarrheal diseases. He also spent time mentoring trainees from around the world. Grant was a true clinical scientist, able to lead scientific discussions with $\mathrm{PhDs}$ and grass roots clinical discussions with clinical colleagues.

Not only was he an exceptional physician, Grant was also a leader. When he had an idea, he gave it his all and you could not help but be pulled along in the vortex. He had more than a few good ideas for the Canadian Association of Gastroenterology (CAG). Grant changed the CAG by giving Canada's gastroenterology community its first international exposure. As Presidentelect, he organized the first Canadian Digestive Diseases Week (CDDW). It was a major change from the traditional Royal He loved to fish the Bow river, hunt prairie chickens, walk across countries (particularly Scotland), search for antique cars, listen to the blues and drink expensive scotch.

Grant graduated from the ACME High School, of which he was very proud, then the University of Alberta Medical School, Edmonton, Alberta. It can come out now that he loved the Oilers, a residual from his university days. He interned and completed residencies in Vancouver, Toronto and Boston (USA). He also held appointments as an instructor in pediatrics at Harvard University and Boston University. After spending several years at The Hospital for Sick Children in Toronto, Ontario, he joined the University of Calgary, Calgary, Alberta, where he held many positions, notably, heading the Division of Pediatric Gastroenterology and Nutrition, holding the Alberta Children's Hospital Foundation Chair in Pediatric Research, Professor and Head of the Department of Pediatrics, medical leader of the Child Health Program and Head of the Regional Department of Pediatrics.

During his 30 years at the Univesity of Calgary, Grant was the Dean of the Medical School for two terms. He was a tireless worker and was instrumental in convincing the Alberta government of the need for a new children's hospital. He loved to tell of the influence of children in the planning that led to such novel changes as low windows, bright colours and a special entrance for the 'chemo kids'. As Dean, and perhaps as a one-time farm boy, he recognized the need for veterinarians and advocated for the creation of the Faculty of Veterinary Medicine, which opened this past September.

Throughout his career, Grant was active with the Canadian Institutes of Health Research, serving on various committees

University of Alberta, Edmonton, Alberta

Correspondence: Dr Robert J Bailey, University of Alberta, 310 - 11010101 Street Northwest, Edmonton, Alberta T5H 4B9.

Telephone 780-421-1029, fax 780-425-5533, e-mail rbailey@ualberta.ca

Received and accepted for publication May 1, 2009 


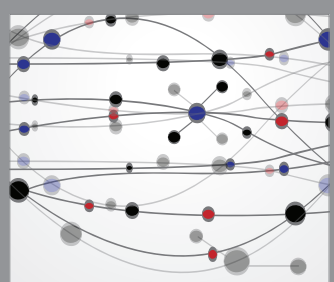

The Scientific World Journal
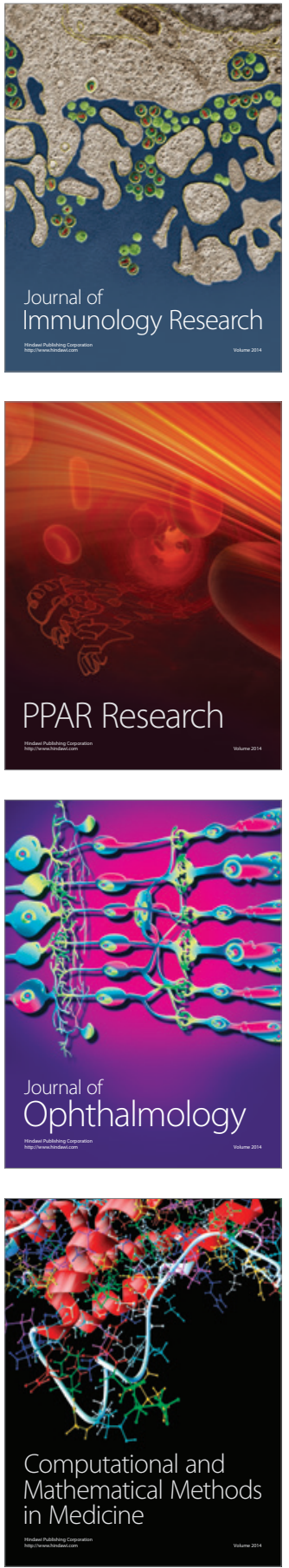

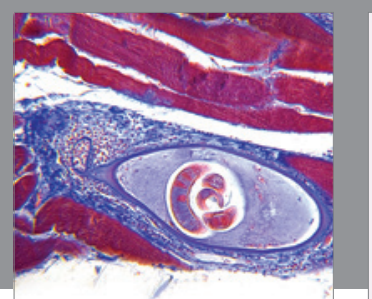

Gastroenterology Research and Practice

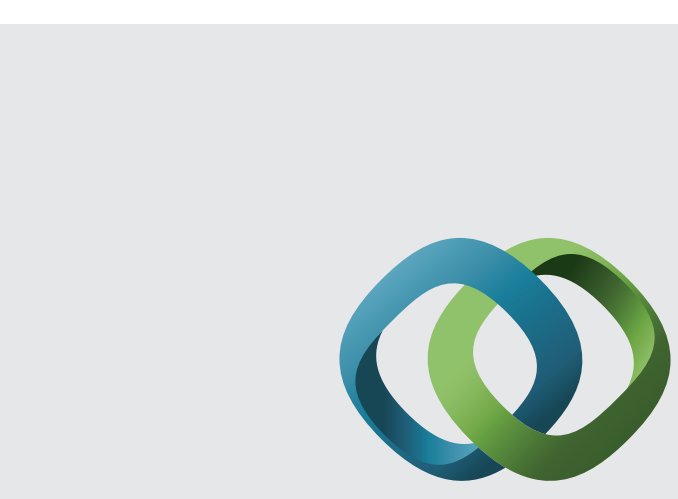

\section{Hindawi}

Submit your manuscripts at

http://www.hindawi.com
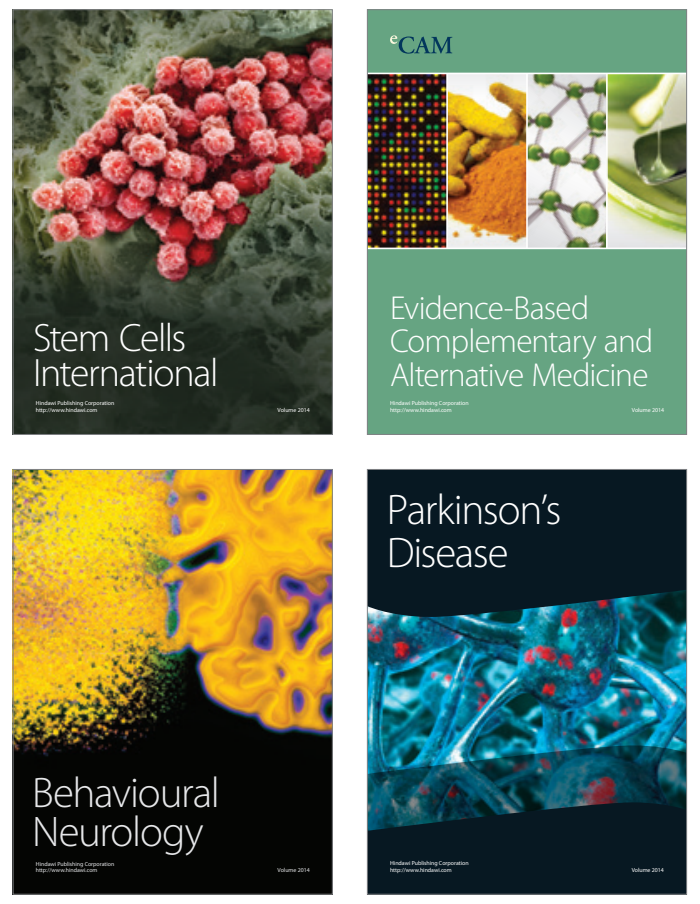
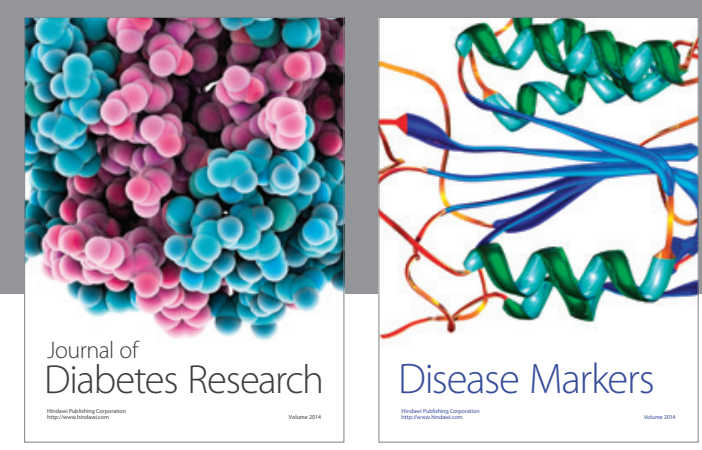

Disease Markers
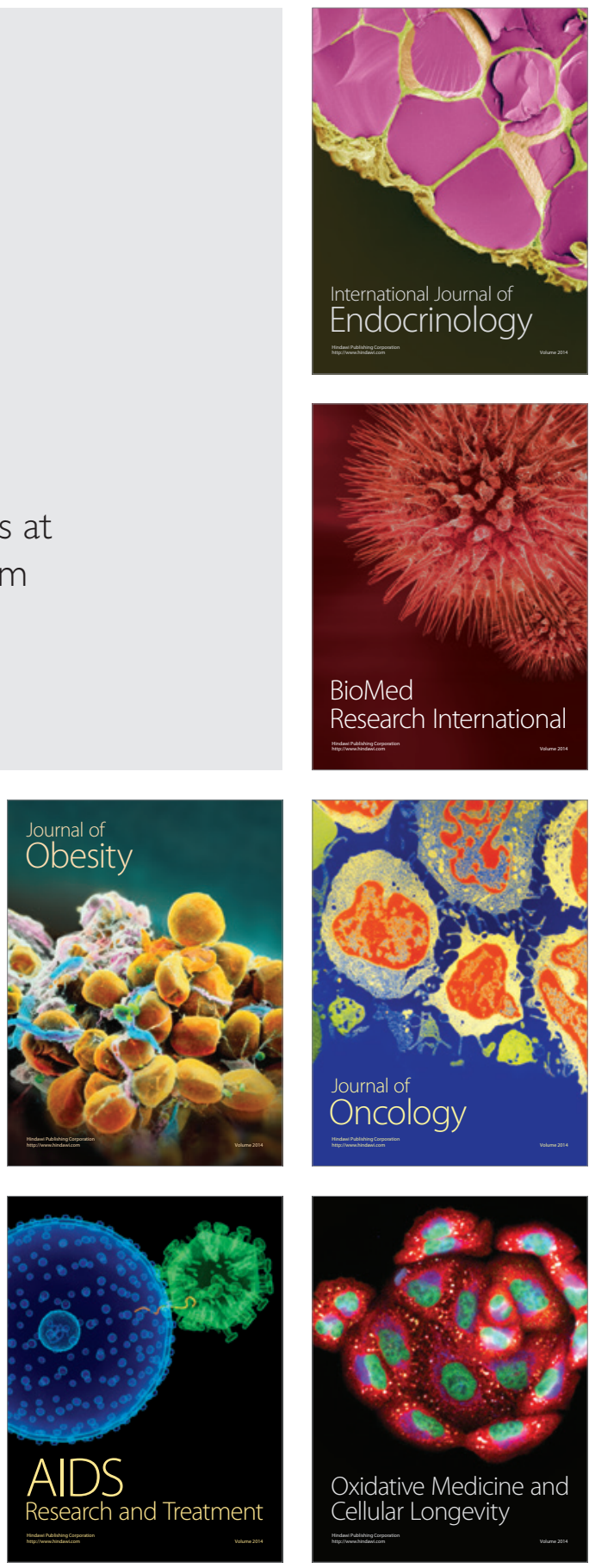